\title{
What Would I Do Differently? Using First Person Voice to Develop Leadership Identity for Health Care Professionals
}

\author{
Ozgur Ekmekci \\ Assistant Professor \\ The George Washington University \\ Department of Clinical Management and Leadership \\ $90023^{\text {rd }}$ Street, NW, Suite 6177 \\ Washington, DC, 20037 \\ ekmekci@gwu.edu
}

\begin{abstract}
Can leadership be taught? Those of us who offer courses on leadership, as part of an academic program, face this question quite often. It is my belief that acquiring more knowledge on leadership does not readily translate into becoming a better leader - especially so at a time in history where leaders have to deal with more complexity and change than ever before (Snowden \& Boone, 2007; Malloch \& Porter-O'Grady, 2009). Leadership is a process of becoming rather than a process of acquiring. In this paper, I argue the need to ground our teaching practices in complex responsive processes (Stacey, 2003), share one such practice we employ in a graduate program for health care professionals, and discuss the implications.
\end{abstract}

\section{Introduction}

Can leadership be taught? Those of us who offer courses on leadership, as part of an academic program, face this question quite often. While there may be a number of different opinions on the matter (Bass, 1990; Bennis, 1989; Kotter, 2001; Kouzes \& Posner, 1997; Washburn, 1998; Yukl, 2002; Zaleznik, 1977), as a faculty member teaching a graduate course on leadership and change for health care professionals, I believe our role is one of facilitation, more so than it is of instruction. We can talk about leadership theories in class, illustrate the construct through research conducted in various domains, and maybe even model what it means to be a leader through our own behavior, but at the end of the day - as faculty - all we can hope for is that our own efforts have somewhat helped our students in their efforts to become better leaders. After all, leadership is a process of becoming rather than a process of acquiring. It is my belief that acquiring more knowledge on leadership does not readily translate into becoming a better leader especially so at a time in history where leaders have to deal with more complexity and change than ever before (Snowden \& Boone, 2007; Malloch \& Porter- 
O'Grady, 2009). With that fundamental belief, in this paper, I argue the need to ground our teaching practices in complex responsive processes (Stacey, 2003), share one such practice we employ in a graduate program for health care professionals, and discuss the implications.

\section{Leadership, Change, and Complex Responsive Processes}

The health care sector is a formidable landscape, which accounts for nearly onesixth of the gross domestic product at over \$2.5 trillion (NCHC, 2009). While this sector is firmly grounded in research and development (Berwick, 2003), there is widespread sentiment that the sector is in serious crisis. James Clifton, Chief Executive Officer of Gallup, Inc., in the opening speech he made at The National Conference on Health Care Consumerism in Arlington, Virginia on December 9, 2008, stated that lack of leadership was the root cause for many problems in health care (2008).

According to a recent poll, four in five Americans feel that the U.S. health system is in need of a fundamental change or a complete overhaul (2008). One of the reasons Americans may not be seeing the desired change anytime soon is because health care professionals are usually reluctant to innovate or initiate change in the face of perceived complexity and risk (Ekmekci \& Turley, 2008). In an environment where the amount of complexity and risk leaders face is likely to increase for the foreseeable future (McAlearney, 2008; Snowden \& Boone, 2007), leadership - which has been named the most critical factor for successful change in a survey of senior executives working for Fortune 500 companies in the United States (Gill, 2003) - will have to play a larger role in envisioning change.

Envisioning change - that is "articulating a compelling vision, mission and strategy", which "connects employees, shareholders, suppliers and customers" (Kets de Vries, Vrignaud, \& Florent-Treacy, 2004, p. 479) - has been found to be one of the 12 key dimensions by which world-class leaders are evaluated. As a matter of fact, some argue that "if leadership is essentially about realizing change, then crafting and articulating a vision of a better future is a leadership prerequisite" (Ibarra \& Obodaru, 2009, p. 65). However, envisioning change starts with challenging the status quo and clearly communicating the direction and speed of change. When communicating the speed and direction of change, leaders must allow their "own emotions to surface" (Conger, 1991, p. 43). A leader's commitment to and belief in the vision is "a cornerstone to becoming inspirational" and may be attained "only after significant periods of exploration, reflection, and effort" (Conger, 1991, p. 43). Only through the proper choice of "words, values, and beliefs" (Conger, 1991, p. 43) can the leader convey confidence through a compelling vision. 
In change efforts that are grounded in linear systems thinking (Stacey, 2003), it may be difficult to create such a compelling vision, since this particular view treats the leader outside of and independent from the environment, as if that individual were an objective observer recommending certain initiatives for the objective system that was being observed. McLagan (2002) and Kotter (1995) argue that many failed transformation initiatives are the result of leaders falsely assuming that organizations will naturally embrace rational and technically-sound plans that have been designed outside of the system itself. Such plans, no matter how much detail they have or regardless of how well they are crafted, are doomed to fail in the absence of a compelling vision (Kotter, 1995; Gill, 2003). In contrast, change efforts that are grounded in complex responsive processes thinking (Stacey, 2003) - because they emerge out of the same environment in which both the leader and the organization co-evolve to create subjective and meaningful transformation - have a better chance of initially producing and then being guided by a compelling vision. Through interactions with other members of the organization, a leader is not only capable of conceptualizing, articulating, and communicating a compelling vision, but is also able to get stakeholders involved in the change efforts by way of iterative gestures and responses (Mead, 1934) even if this is done simply through simulated role play (Guenthner, 2005).

While objectively analyzing a system - as an outside observer - and then planning a strategy for change appears to be an impartial and scientific method for leaders to implement organizational transformation, this approach often fails. The main reason for failure is that by planning the transformation process as an outside observer, leaders usually end up excluding stakeholders - those who will have to carry out the change efforts and those who will have to adapt to the changes from the planning process. By doing so, leaders overlook the need to articulate a compelling vision and the task of connecting this vision to what each stakeholder has to do in order for the desired transformation to take place. The leadership of change (Gill, 2003) has to fully integrate all stakeholders into the transformation process for it to be effective. Such integration relies on establishing a strong leadership identity that is embedded within and becomes part of the organization undergoing transformation.

\section{Developing Leadership Identity: A Graduate Level Application}

\section{Change Proposal Project}

The Department of Clinical Management and Leadership within the School of Medicine at The George Washington University provides degree and certificate programs in Clinical Health Sciences, Clinical Management and Leadership, Clinical Research Administration, and End-of-Life Care. Our programs reinforce an interdisciplinary approach and serve practitioners interested in formalizing 
their educational and professional accomplishments through a degree or certificate in their field of study. We embrace the fundamental concepts of adult learning and encourage collaborative independence within the program. Our students are mainly health care professionals with a significant amount of work experience, who strive to advance their careers by pursuing a higher degree in their field (GWU, 2009).

All of our graduate level programs end with a capstone course that focuses on leading change within the contexts of health professionals, health systems, and health policy. In this course, we present and discuss theories on the topics of organizations, leadership, change, and complexity. We also explore characteristics of personal and professional change leadership in relation to expectations for successful executive leadership and performance in today's dynamic health care environments.

We ask students taking the capstone course to develop a research-supported comprehensive change initiative proposal that demonstrates leadership and competency in the assigned field of graduate study. Students have three months to work on this project. The main objective of this assignment is for students to develop a leadership identity that evolves parallel to their change proposals throughout the course of the semester.

We ask that our students pick an organization with which they are fairly familiar preferably the one for which they are working - and identify an aspect of this organization that they would like to change. Most importantly, when writing their proposals, we ask our students to use first person language and employ active voice in their narrative and require that they structure their proposals, whereby they provide a:

- brief introduction of the organization that gives the reader a sense for the size, location, mission, and operations;

- description of the student's leadership role in the organization;

- definition of the problem the organization currently faces;

- statement of significance indicating why the mentioned problem is important and what will happen if it is not addressed;

- description of the change strategy and target objectives, along with a basic timeline;

- a list of stakeholders (i.e., those who are affected by the problem and those who will be affected by the proposed solution) and a strategy for working with them, along with a discussion of anticipated resistance to change;

- description of how to monitor progress - as measured against target objectives - and how to evaluate success; and 
- a wrap-up discussion, including a statement of why the organization will be a better place as a result of the proposed change effort.

As instructors, we provide regular feedback to each student throughout the proposal development process, constantly encouraging them to envision what they would do and how they would do it, if they were the leader in charge of the proposed initiative. Through such feedback, we also ensure that they properly align all of the components listed above in their presentation. Towards the end of the course, we put our students in groups of three and have each student conduct a formal peer review of proposals for the other two members of the group. We conclude the project with a final instructor evaluation of the proposals.

\section{Student Feedback}

Overall, we get highly-positive feedback from our students regarding their experiences in developing a leadership identity through the articulation of a change proposal. Here is how one student summarizes her experiences, with an emphasis on the positive influence of writing in first person:

To present my thoughts in such a way that it was not only my philosophy on leadership, as it has been molded and shaped through my graduate education, but to do so in my own voice? At first, I was a bit stumped....I was under the misguided assumption that one could not write in first person in a scholarly undertaking - thus the reason that I wrote my first paper in third person. However, once I was given 'permission' to do so, I found it a very creatively freeing experience. I do feel that it has been a worthwhile method that has allowed me to better integrate my learning as I am actually 'placing' myself in that learning.

Another student comments on the experience of being placed directly in the leadership role:

I believe that your method is extremely helpful in allowing us to consider every aspect of leadership that we may not have otherwise considered, if we were not, ourselves, in the leadership role. Additionally, it requires us to organize our thoughts systematically as we develop a plan of action. This will certainly prepare us for leadership roles in the future as we now have 'done' it and will be much more comfortable in these roles. I can see it as a great stress reducer in my future to know that I can save an entire hospital if I need to.... I have done it on paper! Thank you for powerful lessons in leadership.

Similarly, another student draws attention to the power of employing an insider's perspective when approaching transformation:

I personally liked the approach of putting us in the forefront as a leader. I only wish that I had taken this course prior to starting the non-profit. I have gained such knowledge about how I could have better achieved success with the tools I 
have learned. This course has also provided the means to look at my organization as well as other departments internally to understand their strengths and weaknesses.

Many of our students consistently comment on how connecting the self to others has helped them better conceptualize what they would do - as well as how they would do it - when asked to transform an organization. The realization of the interconnected nature of organizational relationships and how they may facilitate or hamper change initiatives comes to life in one of our student's comments: This has been an especially good style of learning for me. My project planning does reflect my actual expectations of how I anticipate things will occur when I actually implement the plan. This has allowed me to play out the scenario and to anticipate barriers that I may not have considered prior to the exercise.

Another student adds to the significance of employing a personal perspective when thinking about change:

I have benefited from this perspective from being placed in the position of a leader. The benefit is to extrapolate and process possibilities from that position. It was helpful and educational for me to look and see who I will want to be more clearly than I ever have before. I have found the process of learning through applying personal perspective to change management to be beneficial.

A student summarizes the difference between acquiring more leadership knowledge versus becoming better as follows:

Putting myself into leadership positions for class assignments has actually helped me gain some insight in my day to day work. What is most interesting to me now is that I feel more like I am being a leader, when I am simply being myself, instead of trying to act like a leader.

Finally, I would like to share the comments of a student who emphasizes how developing a leadership identity helps them conceptualize how they would change an organization, as opposed to how an organization ought to be changed.

I think your model has been very effective in forcing each of us to think about leadership, particularly for us to think about how we would lead organizations or departmental groups.

\section{Implications}

The feedback we receive from our students supports our belief that developing a leadership identity is essential for helping our students become agents of meaningful and sustainable change. First of all, students find it easier to conceptualize, articulate, and implement change, when they establish a strong 
leadership identity. Furthermore, students more effectively construct and communicate a compelling vision, when they employ first person perspective and use active voice in their change proposals.

Thinking about what they would do, allows students to consider their potential actions (i.e., gestures) and others' potential reactions (i.e., responses). In other words, the iterative nature of the gesture-response cycle to which Mead (1934) refers sets into motion a series of complex responsive processes (Stacey, 2003) through which a strategy for organizational change emerges naturally. This type of emergence is necessary, as leaders cannot change an organization without changing themselves and others (i.e., stakeholders). Meaningful and sustainable change cannot be achieved in organizational settings where leaders do not involve stakeholders' in the strategic planning process. Interactions with and through stakeholders are vital elements of the organizational transformation process.

As instructors in leadership programs, we should encourage wider use of first person perspective and active voice by immersing our students in organizational contexts that will allow them to think about what they would do, instead of generically talking about what needs to be done. By allowing our students to use passive voice, we also create a medium in which they can conceal "agency, or responsibility for action." (Germano, 2005, p. 20). Instead of letting our students patch together a wish list - of things they hope will somehow be done - when thinking about change, we should encourage them to specifically consider who will do what, with whom, and by when. In change proposals, the use of passive voice not only distances the writer from the reader, but it also distances the writer from his or her own ideas (Germano, 2005), hence hampering the development of a strong leadership identity. Most importantly, however, readers respond better to the use of active voice, as they sense another human being - a genuine identity vying for their attention and trying to connect with them. That connection is vital for creating a compelling case for change.

In summary, helping our students form a strong leadership identity should be our top priority, if we, as educators, are to have any hope of creating winds of change in the health care domain. We can't lose sight of the probability that a mind that we can transform in our programs today may someday transform the very world in which we all live and work. As hard as it is to believe, when faced with the status quo that one can't quite embrace, the path to transformation almost always starts with a simple question: What would I do differently? 


\section{References}

Bass, B. M. (1990). From transactional to transformational leadership: Learning to share the vision. Organizational Dynamics, 18, 19-31.

Bennis, W. (1989). On becoming a leader. Reading, MA: Addison-Wesley.

Berwick, D. M. (2003). Disseminating innovations in health care. Journal of American Medical Association, 289(15), 1969-1975.

Conger, J. A. (1991). Inspiring others: The language of leadership. Academy of Management Executive, 5(1), 31-45.

Clifton, J. (2008). Personal communication. The National Conference on Health Care Consumerism in Arlington, Virginia on December 9, 2008

Ekmekci, O., \& Turley, C. L. (2008). Duplicate, replicate, speculate, or innovate? How health care managers solve problems? SAM Advanced Management Journal, 73(2), 4-13.

Freed, J. C. (2008). Health care: Change it or tear it down? International Herald Tribune, May 30, 2008.

Germano, W. (2005). Passive is spoken here. Chronicle of Higher Education, 51(33), 20.

Gill, R. (2003). Change management - or change leadership? Journal of Change Management, 3(4), 307-318.

Guenthner, J. F., \& Moore, L. L. (2005). Role playing as a leadership development tool. Journal of Leadership Education, 4(2), 59-65.

GWU (2009). Department of Clinical Management and Leadership. Retrieved on January 9, 2009. http://www.gwumc.edu/healthsci/departments/cml/index.cfm.

Ibarra, H., \& Obodaru, O. (2009). Women and the vision thing. Harvard Business Review, January, 62-70.

Kets de Vries, M. F. R., Vrignaud, P., \& Florent-Treacy, E. (2004). The global leadership life inventory: Development and psychometric properties of a 360degree feedback instrument. Journal of Human Resource Management, 15(3), 475-492. 
Kotter, J. (1995). Leading change. Harvard Business Review, March - April, 5967

Kotter, J. (2001). What leaders really do. Harvard Business Review, December, 85-96.

Kouzes, J. M., \& Posner, B. Z. (1997). The leadership challenge: How to keep getting extraordinary things done in organizations $\left(2^{\text {nd }} e d.\right)$. San Francisco: Jossey-Bass.

Malloch, K., \& Porter-O'Grady, T. (2009). The quantum leader: Applications for the new world of work ( $2^{\text {nd }}$ ed.). Sudbury, MA: Jones and Bartlett Publishers.

McAlearney, A. S. (2008). Using leadership development programs to improve quality and efficiency in healthcare. Journal of Healthcare Management, 53(5), 319-331.

McLagan, P. (2002). Change leadership today, Training \& Development, 56(11), 26-31.

Mead, G. H. (1934). Mind, self and society. Chicago: Chicago University Press.

NCHC. (2009). Facts on the cost of healthcare. Retrieved January 9, 2009, http://www.nchc.org/facts/cost.shtml.

Snowden, D.J., \& Boone, M. A. (2007) Leader's framework for decision making. Harvard Business Review, November, 69-76.

Stacey, R. D. (2003). Complexity and group processes: A radically social understanding of individuals. Routledge, London.

Wallick, W. G. (2002). Healthcare managers' roles, competencies, and outputs in organizational performance improvement. Journal of Healthcare Management, 47(6), 390-401.

Washburn, J. (1998). From where will the leaders come? Revisited. Journal ofEducation for Business, 73(4), 251-253.

Yukl, G. (2002). Leadership in Organizations, $5^{\text {th }}$ ed., Prentice Hall, New Jersey.

Zaleznik, A. (1977). Managers and leaders: Are they different? Harvard Business Review, May-June, 67-78. 